\title{
Carbon and hydrogen isotopic compositions and their evolutions of gases generated by herbaceous swamp peat at different thermal maturity stages
}

\author{
DUAN Yi ${ }^{*}$, ZHANG XiaoLi, SUN Tao, WU BaoXiang, HE JinXian \& XU Li \\ Key Laboratory of Petroleum Resources Research, Institute of Geology and Geophysics, Chinese Academy of Sciences, Lanzhou 730000, China
}

Received October 19, 2010; accepted December 14, 2010

\begin{abstract}
Coalbed methane (CBM) accumulation models include continuous gas accumulation and staged gas accumulation. However, studied on the geochemical characteristics and indices to evaluate staged accumulation CBM are lacking. This study for the first time obtained the carbon and hydrogen isotopic compositions of methane and ethane generated at different evolution stages using thermal simulation of samples prepared by treating an herbaceous swamp peat at different temperatures. The results showed that the carbon isotopic compositions of methane and ethane were obviously affected by the thermal evolution level of the starting sample, while the hydrogen isotopic compositions were closely related to the maturity of gases. The carbon and hydrogen isotopic compositions of gases generated by coal-forming organic matter with $R_{\mathrm{o}}$ values from $1.2 \%, 1.7 \%, 2.4 \%, 3.2 \%$ and $3.7 \%$ to $5.2 \%$ were determinated. The relationship between $R_{\mathrm{o}}$ values and the carbon and hydrogen isotopic compositions of gases generated by coal-forming organic matter at different evolution stages as well as the carbon or hydrogen isotopic relationships between methane and ethane were established. The results provide a scientific basis for studying the genesis of CBM generated at different maturity intervals and understanding the geochemical characteristics of staged accumulation CBM. These results were applied to a case study on CBM from the southern Qinshui basin, and it was found that the CBM accumulated after the Middle Jurassic and was characteristic of staged gas accumulation. This is consistent with the result of geological studies, and further showed that the results of thermal simulation experiments are very important for evaluating the genesis of natural CBM.
\end{abstract}

peat, simulation experiment, coalbed methane, staged gas accumulation, carbon and hydrogen isotopes, Qinshui Basin

Citation: Duan Y, Zhang X L, Sun T, et al. Carbon and hydrogen isotopic compositions and their evolutions of gases generated by herbaceous swamp peat at different thermal maturity stages. Chinese Sci Bull, 2011, 56: 1383-1389, doi: 10.1007/s11434-011-4356-8

Coalbed gas is an unconventional natural gas that is derived from and accumulated in coal seams [1]. As a new type of clean energy, coalbed methane (CBM) has become a research focus of petroleum geology [1-6]. Carbon and hydrogen contents of CBM are one of the most effective methods to understand the genesis of CBM. CBM accumulation models include continuous gas accumulation and staged gas accumulation. The continuous gas accumulation model has been used previously to study CBM genesis [7-14]. However, the studies on geochemical characteristics and evaluation indices of staged accumulation CBM are

*Corresponding author (email: duany@ns.lzb.ac.cn) lacking. The isotopic compositions of coalbed gas derived from coal-forming material at different evolution stages should be different. Isotope data obtained by thermal simulation experiments of staged hydrocarbon generation can provide useful scientific evidence for understanding the isotopic geochemical characteristics of staged accumulation CBM.

Peat and coal with different maturities have generally been used as samples for thermal simulation experiments [11,12,15-19]. Hydrocarbon generation by coal-forming material occurs throughout the whole coalification process, including both early stage and late stage. The early stage of coalification from peat to brown coal is mainly via 
low-temperature biogeochemical processes, while the later stage from brown coal to anthracite coal is mediated by higher temperature physical and chemical processes [20]. Therefore, thermal simulation experiments using peat as the coal-forming original matter can model the whole process of hydrocarbon generation during coalification. Yao et al. [17] have performed a comparative study of experimental maturation of peat, brown coal and subbituminous coal, and found that they have similar pathways of thermal evolution except that the gaseous product from peat has a lower relative content of $\mathrm{CO}_{2}$. Duan et al. [11,12] obtained similar results in simulation experiments of peat and different rank coals, and observed that the carbon isotopic compositions of methane generated from peat are lighter than those from different rank coals. This shows that peat contains earlier components of coal-forming material, thus it can be used for simulation experiments of hydrocarbon generation.

To understand the isotopic compositions and evolution of pyrolysis gases in simulation experiments of staged hydrocarbon generation (as well as obtain some indications on the isotopic genesis of staged accumulation CBM), five starting samples were prepared by pyrolysis of herbaceous swamp peat at temperatures of $250,300,350,400$ and $450^{\circ} \mathrm{C}$. Then, simulation experiments were performed on the five starting samples, and carbon and hydrogen isotopic compositions and fractionations of pyrolysis gases with different maturity were studied. The implications of the results for understanding CBM genesis were also discussed.

\section{Samples and experiments}

Black herbaceous swamp peat was collected from Yujiatun $\left(43^{\circ} 15^{\prime} 43^{\prime \prime} \mathrm{N}\right.$; $\left.128^{\circ} 20^{\prime} 21^{\prime \prime} \mathrm{E}\right)$, Dunhua in Jilin Province in August of 2008, from a depth of $0.6-1.25 \mathrm{~m}$, and had an organic carbon content of approximately $30 \%$. The sampling area has an altitude of $568 \mathrm{~m}$ above sea level, and a cold moist climate (with average annual temperature of $2.6^{\circ} \mathrm{C}$ and average rainfall of $632 \mathrm{~mm}$ ). Plants in this area are mainly herbaceous.

The peat was dried at room temperature, and then crushed to 60 mesh. This powdered peat (about $1300 \mathrm{~g}$ ) was divided into five samples, and then each sample was placed into a stainless steel reactor. The reactors containing the samples were evacuated, backfilled with argon and then sealed, and heated for $72 \mathrm{~h}$ in a temperature-programmed furnace with temperature controller at temperatures of 250 , $300,350,400$ and $450^{\circ} \mathrm{C}$, respectively. Thus, five starting samples were prepared. Afterwards, the five starting samples were pyrolyzed individually for $72 \mathrm{~h}$ in a sealed stainless steel reactor at temperatures ranging from $50^{\circ} \mathrm{C}$ above the prepared sample temperature to $650^{\circ} \mathrm{C}$ with an interval of $50^{\circ} \mathrm{C}$. Samples sizes varied with temperature interval difference. The reactors containing the starting samples were flushed three times with helium to remove air, sealed under argon, and then heated in a temperaturecontrolled furnace rapidly to the desired pyrolysis temperature.

The carbon and hydrogen isotopic compositions of the gases collected at each temperature intervals were measured by Gas Chromatograpy-Thermal Conversion-Isotope Ratio Mass Spectrometry (GC-TC-IRMS). The GC was the Agilent 6890 and the IRMS is a Thermo Finnigan Delta plus XP (Bremen, Germany), while the pyrolysis device $\left(1440^{\circ} \mathrm{C}\right)$ between them is connected by a GC-CIII. The GC was equipped with a $\mathrm{HP}-\mathrm{Al} / \mathrm{KCl}$ fused silica capillary $\mathrm{Al}_{2} \mathrm{O}_{3}$ column (50 $\mathrm{m} \times 0.53 \mathrm{~mm}$ i.d., $15 \mu \mathrm{m}$ film thickness) for Analyses of the hydrogen isotopes and a CP-Carbobond fused silica capillary column $(25 \mathrm{~m} \times 0.53 \mathrm{~mm}$ i.d., $10 \mu \mathrm{m}$ film thickness) for analyses of the carbon isotopes. Helium was used as the carrier gas. The temperature was programmed from 30 to $180^{\circ} \mathrm{C}$ at $15^{\circ} \mathrm{C} / \mathrm{min}$ and kept for $5 \mathrm{~min}$ for analyses of the hydrogen isotopes, and from 30 to $240^{\circ} \mathrm{C}$ at $15^{\circ} \mathrm{C} / \mathrm{min}$, and kept for $15 \mathrm{~min}$ for analyses of the carbon isotopes. The analytic precisions of carbon and hydrogen isotopic compositions are about $0.3 \%$ and $3 \%$, respectively. The vitrinite reflectance $\left(R_{\mathrm{o}}\right)$ of the residual solids after pyrolysis was measured to within a standard deviation of less than $0.07 \%$.

\section{Results and discussion}

\subsection{Carbon and hydrogen isotopic compositions and evolutions of gases with different thermal maturity}

To understand the carbon and hydrogen isotopic compositions and evolutions of gas in the process of CBM generation, staged thermal simulation experiments were performed on a herbaceous swamp peat. For the five starting samples prepared at $250,300,350,400$ and $450^{\circ} \mathrm{C}$, respectively, the isotopic compositions and evolutions of gases generated at temperatures ranging from the prepared sample temperature plus 50 to $650^{\circ} \mathrm{C}$ in $50^{\circ} \mathrm{C}$ steps exhibited certain patterns. In general, biochemical effects are significant during early natural coalification. However, gas generation from these prepared samples is mainly affected by thermal conditions. This is because the starting samples were prepared at a minimum of $250^{\circ} \mathrm{C}$ corresponding to $R_{\mathrm{o}}$ values of $0.72 \%$ and gas coal stage. Therefore, these results are relevant for determining the geochemical characteristics of CBM generated at different maturity stages.

(1) The carbon isotopic compositions of methane generated from the five starting samples prepared at 250, 300, 350,400 and $450{ }^{\circ} \mathrm{C}$ range from $-40.0 \%$ to $-27.5 \%$, $-39.8 \%$ o to $-28.2 \%$ o, $-34.6 \%$ to $-27.7 \%$ o, $-27.5 \%$ o to $-25.9 \%$ and $-27.2 \%$ to $-26.5 \%$ (Figure 1 ), respectively, and average values are given in Table 1. As shown in Figure. 1 , the $\delta^{13} \mathrm{C}$ values of methane generated from the five simulated samples gradually increased with increasing pyrolysis temperature. The difference in carbon isotopic 


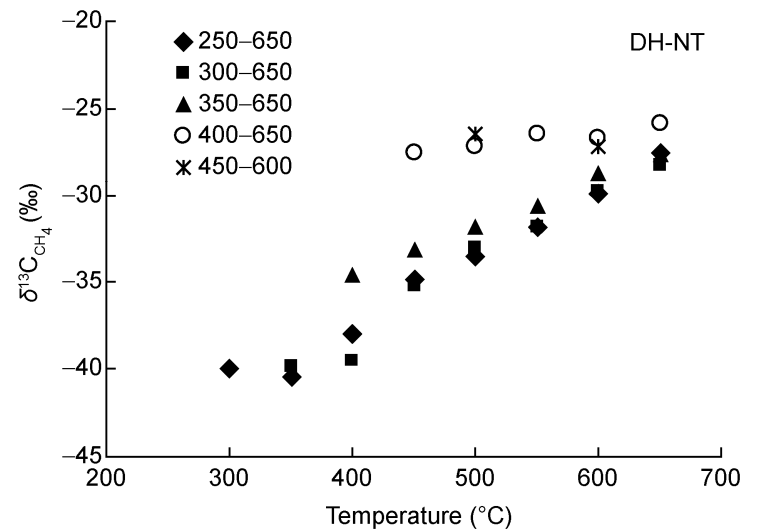

Figure $1 \delta^{13} \mathrm{C}$ of methane vs. pyrolysis temperature. Notation: $250-650$ meas that a sample prepared at $250^{\circ} \mathrm{C}$ was heated from $300^{\circ} \mathrm{C}$ to $650^{\circ} \mathrm{C}$. This notation also applies to later figures.

Table 1 Average $\delta^{13} \mathrm{C}$ and $\delta \mathrm{D}(\%)$ of methane, ethane and $\mathrm{CO}_{2}$ generated from peat of different $R_{0}$ intervals

\begin{tabular}{cccccccc}
\hline Sample & $R_{\mathrm{o}}(\%)$ & $\delta^{13} \mathrm{C}_{\mathrm{CH}_{4}}$ & $\delta \mathrm{D}_{\mathrm{CH}_{4}}$ & $\delta^{13} \mathrm{C}_{\mathrm{CO}_{2}}$ & $\delta^{13} \mathrm{C}_{\mathrm{C}_{2} \mathrm{H}_{6}}$ & $\delta^{13} \mathrm{C}_{\mathrm{C}_{3} \mathrm{H}_{8}}$ & $\delta \mathrm{D}_{\mathrm{C}_{2} \mathrm{H}_{6}}$ \\
\hline $250-650$ & $1.2-5.7$ & -34.5 & -228 & -17.9 & -27.8 & -28 & -209 \\
$300-650$ & $1.7-5.7$ & -33.9 & -219 & -17.6 & -28.9 & -28.7 & -200 \\
$350-650$ & $2.4-5.7$ & -31.1 & -199 & -16.3 & -26.2 & -24.2 & -166 \\
$400-650$ & $3.2-5.7$ & -27.8 & -151 & -16.4 & -18.8 & & -107 \\
$450-600$ & $3.7-4.8$ & -26.9 & -144 & -15.4 & & & \\
\hline
\end{tabular}

Here " $250-650$ " means that the sample prepared at $250^{\circ} \mathrm{C}$ was heated from 300 to $650^{\circ} \mathrm{C}$. The isotope values of each gas are an average value at each simulation temperature (or $R_{\mathrm{o}}$ ) intervals, and represents the isotopic composition of each gas member generated in this evolution stage.

compositions of methane generated from the studied samples is most obvious at lower pyrolysis temperature, and shows that the higher the evolution of the starting sample, the heavier the carbon isotopic compositions of the generated methane. However, at high pyrolysis temperature, the carbon isotopic compositions of methane tend to be similar among the samples. It was observed that the $\delta^{13} \mathrm{C}$ values and evolutions of methane generated from the samples prepared at 400 and $450^{\circ} \mathrm{C}$ are very similar.

(2) The carbon isotopic compositions of ethane generated from the first three samples range from $-32.1 \%$ o to $-23.3 \%$, $-31.8 \%$ o to $-23.2 \%$ and $-29.0 \%$ o to $-23.1 \%$ (Figure 2 ), respectively, and average values are given in Table 1 . The carbon isotopic composition of ethane generated at $450^{\circ} \mathrm{C}$ from the sample prepared at $400^{\circ} \mathrm{C}$ is $-18.8 \%$ (Figure 2 and Table 1). Ethane was mainly generated from the samples prepared at 250,300 and $400^{\circ} \mathrm{C}$, and pyrolyzed at less than $500^{\circ} \mathrm{C}$. The carbon isotopic composition of ethane from the same sample became heavier with increasing pyrolysis temperature. The relationship between methane and ethane generated at the same pyrolysis temperature is $\delta^{13} \mathrm{C}_{1}<\delta^{13} \mathrm{C}_{2}$.

(3) The hydrogen isotopic compositions of methane generated from the five samples range $-335 \%$ to $-151 \%$, $-298 \%$ o to $-150 \%$ o, $-263 \%$ o to $-135 \%$ o, $-225 \%$ o to $-112 \%$ o and $-217 \%$ o to $-119 \%$ (Figure 3 ), respectively, and average values are given in Table 1. The hydrogen isotopic compositions of generated methane became heavier with increasing pyrolysis temperature. The higher the evolution level of the starting samples, the heavier the hydrogen isotopic compositions of the generated methane. At the same time, the hydrogen isotopic compositions of methane prepared at 400 and $450^{\circ} \mathrm{C}$ were similar.

(4) The hydrogen isotopic compositions of ethane generated from the first three samples are from $-265 \%$ to $-112 \%$ o $-250 \%$ o to $-100 \%$ and $-222 \%$ o to $-102 \%$ (Figure 4 ), respectively, and average values are given in Table 1. The hydrogen isotopic composition of ethane generated at $450^{\circ} \mathrm{C}$ from the sample prepared at $400^{\circ} \mathrm{C}$ is $-107 \%$ (Figure 4 and Table 1). The hydrogen isotopic composition of ethane from the same sample became heavier with increasing pyrolysis temperature. The relationship between methane and ethane generated at the same pyrolysis temperature is $\delta \mathrm{D}_{\mathrm{C} 1}<\delta \mathrm{D}_{\mathrm{C} 2}$.

\subsection{Relationship between $R_{0}$ and carbon and hydrogen isotope of gas generated at different evolution stages}

According to the thermokinetic fractionation mechanism of

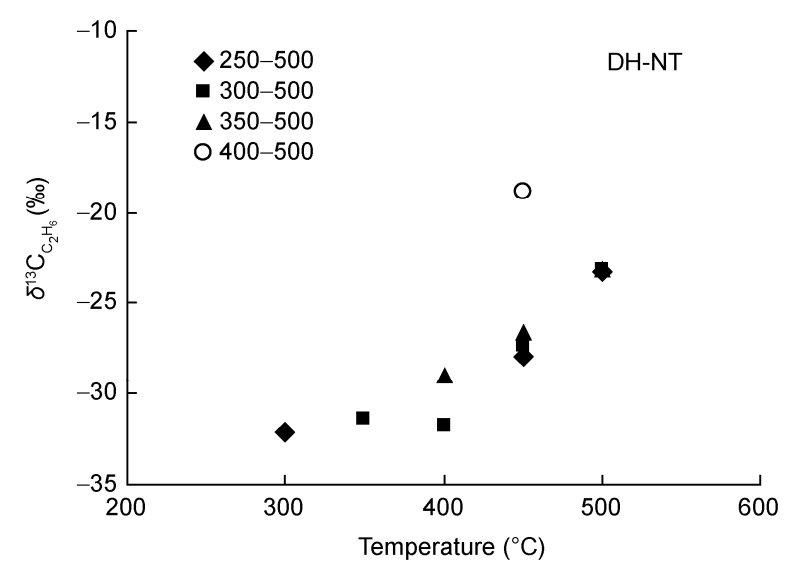

Figure $2 \delta^{13} \mathrm{C}$ of ethane vs. pyrolysis temperature.

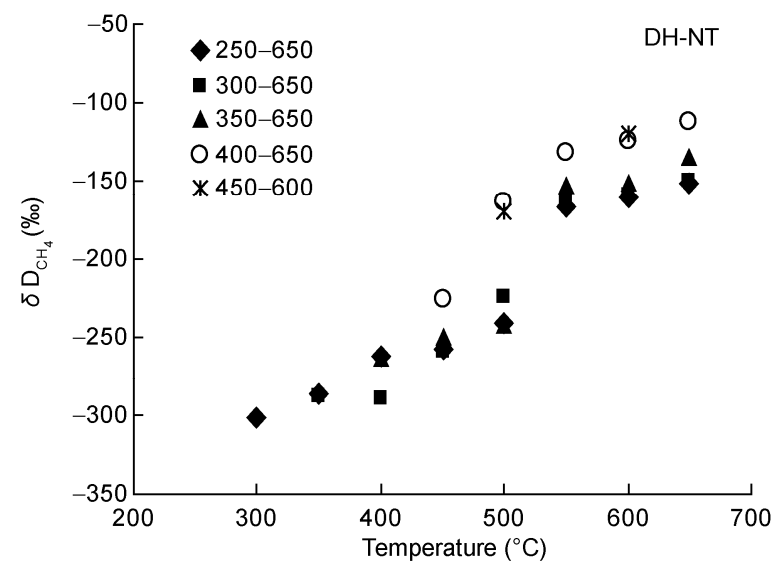

Figure $3 \delta \mathrm{D}$ of methane vs. pyrolysis temperature. 


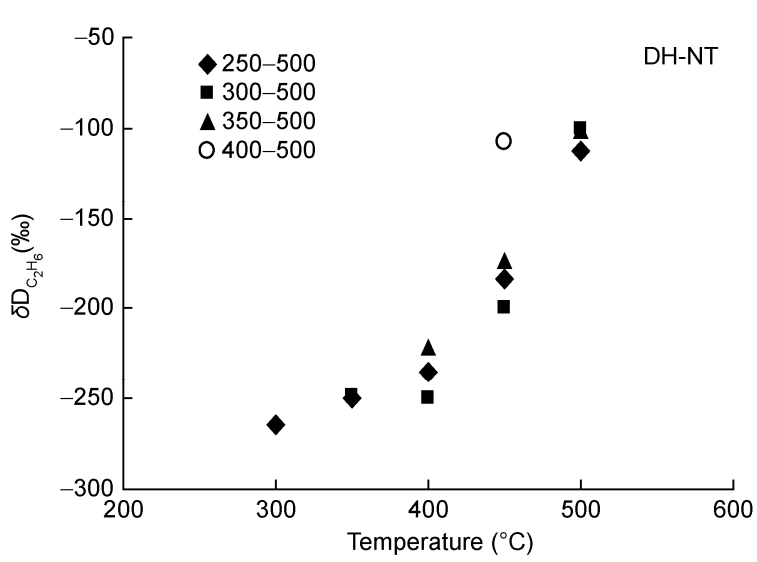

Figure $4 \delta \mathrm{D}$ of ethane vs. pyrolysis temperature.

carbon and hydrogen isotopes of pyrolysis gases generated from herbaceous swamp peat, a mathematical expression relating the compositions of carbon and hydrogen isotopes of gases to $R_{\mathrm{o}}$ can be established [21,22]. This can help to understand the relationship between the carbon and hydrogen isotopic compositions of CBM and the evolution level of organic matter in the source rock and thus study the genesis of CBM [21,22]. Figure 5 shows the correlation between the carbon isotopic compositions of methane generated from the five samples with different maturity and $R_{\mathrm{o}}$ values of the pyrolysis solid products. The carbon isotopic compositions and their evolutions of pyrolysis methane from the samples prepared at 250,300 and $350^{\circ} \mathrm{C}$ were similar, and the expression for these samples is $\delta^{13} \mathrm{C}_{1}=3.00$ $R_{0}-44.19$. Similarly, the $\delta^{13} \mathrm{C}_{1}-R_{\mathrm{o}}$ relationship for samples prepared at 400 and $450^{\circ} \mathrm{C}$ is $\delta^{13} \mathrm{C}_{1}=0.42 R_{0}-28.58$. The correlation for samples prepared at 250,300 and $350^{\circ} \mathrm{C}$ is good, with $R^{2}=0.9322$. It was observed that the slope of the mathematical relationship became smaller and the intercept of ordinates became bigger with increasing evolution levels of the starting samples.

Figure 6 shows the correlation between the carbon isotopic compositions of ethane generated from the samples prepared at 250,300 and $350^{\circ} \mathrm{C}$ and $R_{\mathrm{o}}$ values of the solid pyrolysis products. The carbon isotopic compositions and their evolutions of pyrolysis ethane were very similar among these samples, and there are good correlations between their carbon isotopic compositions and $R_{\mathrm{o}}$ values. In addition, the carbon isotopic compositions of pyrolysis ethane from the sample prepared at $400^{\circ} \mathrm{C}$ was significantly heavier than those from the other three samples.

Figure 7 shows the correlation between the hydrogen isotopic compositions of pyrolysis methane and $R_{\mathrm{o}}$ values of pyrolysis solid products. The hydrogen isotopic compositions and their evolutions of pyrolysis methane were very similar among the samples prepared at $250,300^{\circ} \mathrm{C}$ and $350^{\circ} \mathrm{C}$, and could be divided into three evolution stages. Stage 1 (less than $3.7 \% R_{\mathrm{o}}$ ) was characterized by a slower increase in $\delta^{13} \mathrm{D}_{\mathrm{Cl}}$; stage $2\left(3.7 \%-4.1 \% R_{\mathrm{o}}\right)$ by a rapid in-

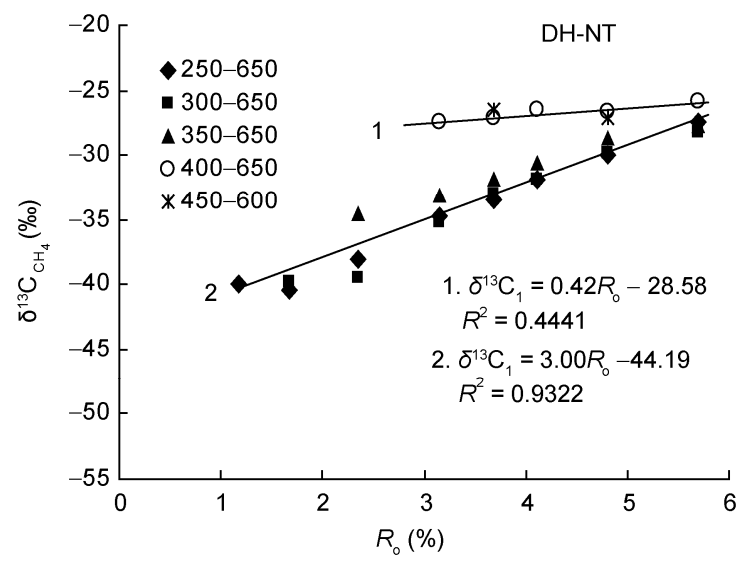

Figure $5 \delta^{13} \mathrm{C}$ of methane vs. $R_{\mathrm{o}}$ values.

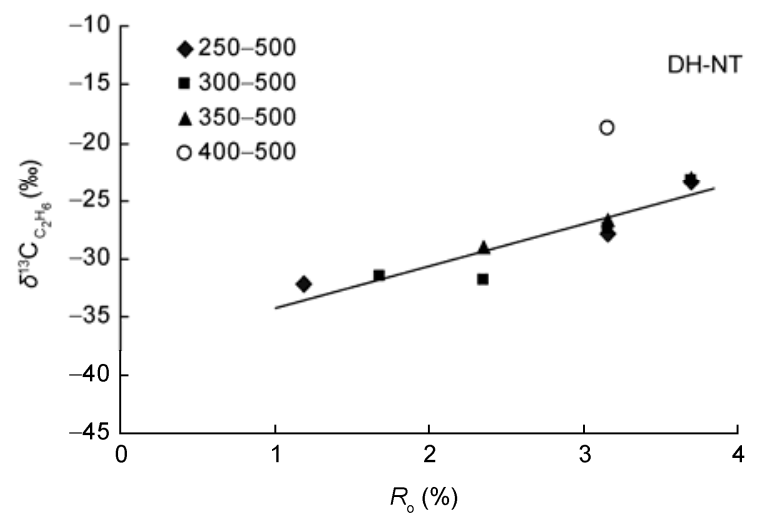

Figure $6 \delta^{13} \mathrm{C}$ of ethane vs. $R_{\mathrm{o}}$ values.

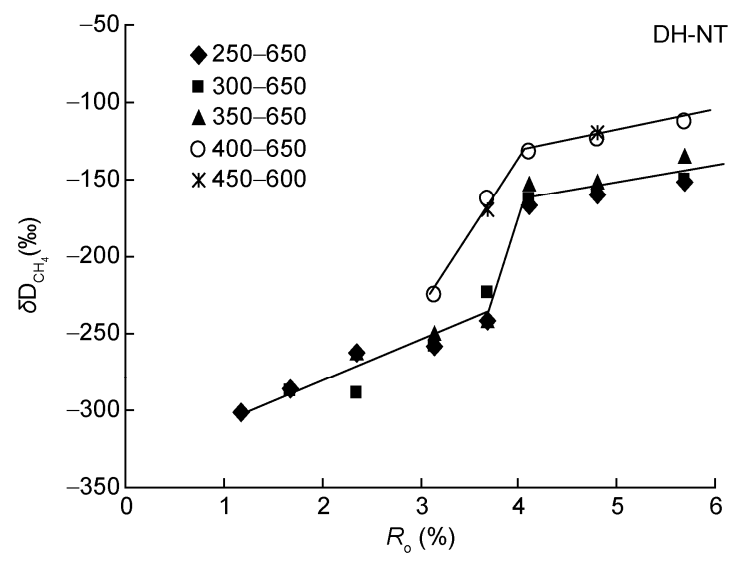

Figure $7 \delta$ D of methane vs. $R_{\mathrm{o}}$ values.

crease in $\delta^{13} \mathrm{D}_{\mathrm{Cl}}$; and stage 3 (more than $4.1 \% R_{\mathrm{o}}$ ) by a slow increase in $\delta^{13} \mathrm{D}_{\mathrm{C} 1}$ values. This shows that the hydrogen isotopes of pyrolysis methane have the biggest thermokinetic fractionation between $3.7 \%$ and $4.1 \% R_{\mathrm{o}}$. The hydrogen isotopic compositions and their evolutions of methane generated from the samples prepared at 400 and $450^{\circ} \mathrm{C}$ were also very similar, and could be divided into two evolu- 
tion stages. The first stage occurred below $4.1 \% R_{0}$. In this stage, $\delta^{13} \mathrm{D}_{\mathrm{C} 1}$ values increased rapidly. The second stage was more than $4.1 \% R_{0}$, and featured a slow increase in $\delta^{13} \mathrm{D}_{\mathrm{C} 1}$ values. However, the evolution mechanism which gives this three or two stage variation in hydrogen isotopes of pyrolysis methane is unclear.

Ethane generated from the samples prepared at 250, 300 and $350^{\circ} \mathrm{C}$ has very similar the hydrogen isotopic compositions and evolutions (Figure 8). The hydrogen isotopic compositions of ethane consistently became heavier with increasing $R_{\mathrm{o}}$ value. The hydrogen isotope composition of ethane generated from the sample prepared at $400^{\circ} \mathrm{C}$ is heavier than those from the other three samples at the same $R_{\mathrm{o}}$ value.

These data show that the carbon and hydrogen isotopic compositions of both methane and ethane generated from all samples studied became heavy with increasing evolution level. This means that the original evolution level of coal will obviously affect the carbon and hydrogen isotopic compositions of methane and ethane of CBM. The similar carbon isotopic evolution pathways of methane and ethane are characteristic of gas generation from a single parent material. These results provide a basis for studying the genesis of CBM in natural basin with different evolution features. In particular, the relationship between the carbon and hydrogen isotopic compositions of gases and $R_{\mathrm{o}}$ values for peat as the original matter of coal reflect the carbon and hydrogen isotopic evolution characteristics of methane and ethane from CBM formed at the different maturity stages during coalification.

\subsection{Implications for recognizing the genesis of CBM}

As the formation processes of many CBM-bearing basins in the world are multi-period, CBM genesis mostly exhibits the characteristics of staged gas accumulation. The carbon and hydrogen isotopic compositions of methane and ethane generated at different thermal evolution stages and their evolution laws were acquired for the first time by simula-

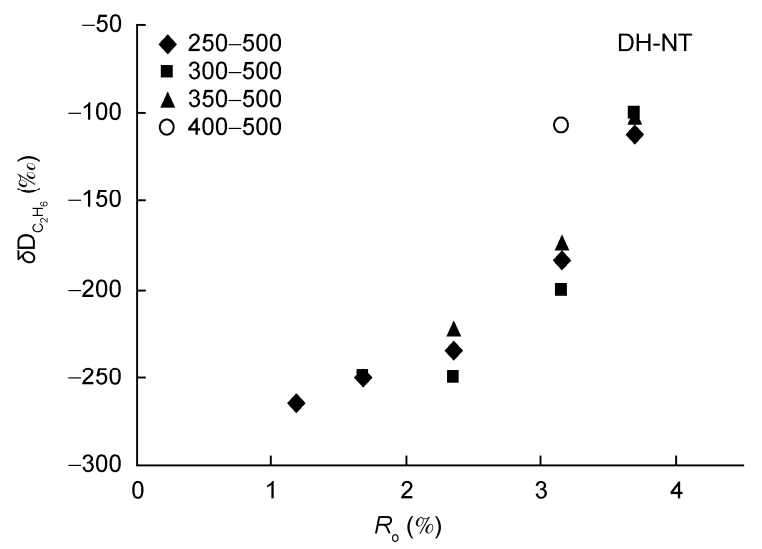

Figure $8 \delta$ D of ethane vs. $R_{0}$ values. tion experiment on peat (Table 1), and these provided scientific data to geochemical characteristics and genesis of CBM.

Figure 9 shows the relationship between carbon and hydrogen isotopic compositions of methane. The carbon isotopic compositions of methane are principally related to the evolution level of the starting samples, while the hydrogen isotopic compositions are mainly affected by gas maturity. This plot can be used to evaluate the genesis of CBM generated from different evolution stages of coal or different maturity levels of gas. Figure 10(a) and (b) show the relationships of $\delta^{13} \mathrm{C}$ and $\delta \mathrm{D}$ between methane and ethane, respectively. The mathematical expressions for the samples studied are $\delta \mathrm{C}_{\mathrm{C} 1}=0.78 \delta^{13} \mathrm{C}_{\mathrm{C} 2}-13.77$ and $\delta \mathrm{D}_{\mathrm{C} 1}=0.36 \delta \mathrm{D}_{\mathrm{C} 2}$ -194.07, and good correlation, with $R^{2}=0.8346$ and 0.8570 , respectively, are present. These relationships showed that carbon and hydrogen isotopic compositions of methane and ethane became heavy with increasing maturity, so this plot can be used to assess the genesis of CBM. At the same time, the correlogram of $\delta \mathrm{D}$ values between methane and ethane can also be used to identify CBM from different coalification stages. In addition, the relationships between $\delta^{13} \mathrm{C}$ and $\delta \mathrm{D}$ of gases generated from coal-forming organic matter at different evolution stages and $R_{\mathrm{o}}$ values can be used as indicators of the genesis and evolution degree of CBM.

For example, CBM from Carboniferous Taiyuan Formation and Middle Lower Permian Shanxi Formation (with $R_{\mathrm{o}}$ value of $2.8 \%-4.8 \%$ ) in the southern Qinshui basin has carbon isotopic compositions from $-33.7 \%$ o to $-30.2 \%$ [23] and the hydrogen isotopic compositions of about $-200 \%$ to $-160 \%$ (provided by Tao Mingxin). These values are similar to $\delta^{13} \mathrm{C}$ values $(-33.9 \%$ to $-31.1 \%$ o $)$ and $\delta \mathrm{D}$ values $(-219 \%$ o to $-199 \%$ ) of methane generated from herbaceous swamp peat at $R_{\mathrm{o}}$ value intervals of $1.7 \%-5.7 \%$ and $2.4 \%$ $-5.7 \%$. This shows that the CBM in the southern Qinshui basin was generated from coal with a maturity of $>1.7 \% R_{0}$, indicating a feature of staged accumulation CBM. This is consistent with the results of geological studies of CBM

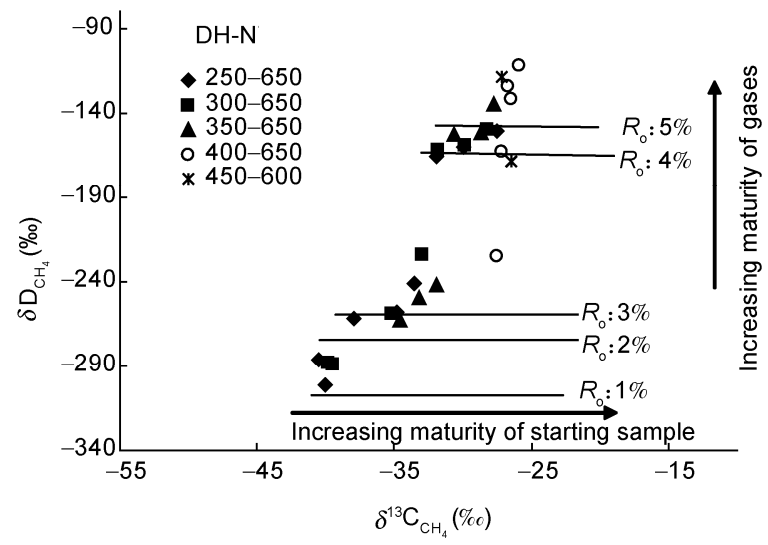

Figure 9 Correlation of $\delta^{13} \mathrm{C}$ and $\delta \mathrm{D}$ values of methane. 

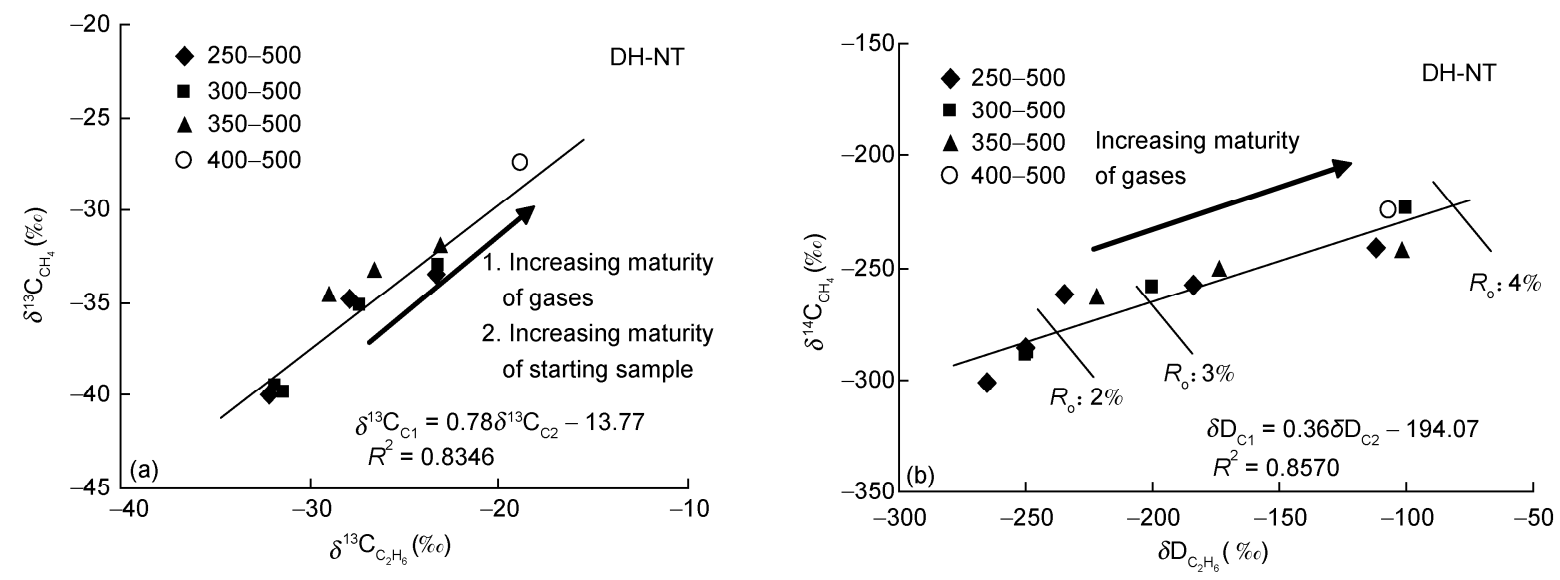

Figure 10 Correlations between $\delta^{13} \mathrm{C}$ of methane and ethane (a) and $\delta \mathrm{D}$ of methane and ethane (b).

genesis in this area. The geological research shows that the CBM generated at the end of the Late Triassic end in this area was destroyed because of uplifting. The CBM in the southern Qinshui Basin was generated and effectively sealed during the Late Jurassic-Late Cretaceous. Moreover, the $R_{\max }$ value of coal is $1.75 \%$ at the end of the Middle Jurassic and $4.05 \%$ at the end of the Late Cretaceous [24]. These are within the range of $R_{\mathrm{o}}$ values in this study $[25,26]$.

\section{Conclusions}

To understand the genesis of $\mathrm{CBM}$ and the stable isotopic geochemical characteristics of staged accumulation CBM, thermal simulation experiments were performed on five samples prepared from herbaceous swamp peat treated at $250,300,350,400$ and $450^{\circ} \mathrm{C}$ for $72 \mathrm{~h}$, and the carbon and hydrogen isotopic compositions and their influencing factors were studied.

Positive correlations between carbon and hydrogen isotopic values of methane and ethane and pyrolysis temperature are present. The higher the evolution level of the starting samples, the heavier the hydrogen isotopic compositions of the methane generated. However, the difference in hydrogen isotopic compositions among the samples is less than that of carbon isotopic compositions. The carbon isotopic compositions of methane and ethane are influenced by the evolution level of the starting sample, while the hydrogen isotopic compositions are mainly related to the maturity of the gas.

The relationship between the carbon and hydrogen isotopic compositions of gases generated by coal-forming material at different evolution stages and $R_{\mathrm{o}}$ values as well as the relationship of carbon or hydrogen isotopic compositions between methane and ethane were established. This provides scientific evidence for studying the genesis of CBM generated at different maturity intervals.
These research results were applied to a case study of $\mathrm{CBM}$ in the southern Qinshui basin. It was suggested that $\mathrm{CBM}$ in this area was accumulated after the Middle Jurassic and characterized by staged gas accumulation. The results obtained from the thermal simulation experiments are important to understand the genesis of natural CBM.

We thank the reviewers and editors who helped improve this manuscript. This work was supported by the National Natural Science Foundation of China (40872092 and 40772069), the "Technology Support Gansu" Project, Chinese Academy of Sciences and the National Basic Research Program of China (2005CB422105).

1 Clayton $\mathbf{J}$ L. Geochemistry of coalbed gas-A review. Int $\mathbf{J}$ Coal Geol, 1998, 35: 159-173

2 Kotarba M J. Isotopic geochemistry and habitat of the natural gases from the Upper Carboniferous Zacier coal-bearing Formation in the Nowa Ruda coal district (Lower Silesia, Poland). Org Geochem, 1990, 16: 549-560

3 Liu D M, Yang Q, Tang D Z. Reaction kinetics of coalification in Ordos Basin, China. In: Yang Q, ed. Geology Fossil Fuels-coal. Utrecht: The Netherlands, 1997. 147-159

4 Qin Y, Tang X Y, Ye J P, et al. Characteristics and originals of stable carbon isotope in coalbed methane of China (in Chinese). J Chin Univ Mining Tech, 2000, 29: 113-119

5 Kotarba M J, Rice D D. Composition and origin of coalbed gases in the Lower Silesian basin, southwest Poland. Appl Geochem, 2001, 16: 895-910

6 Zhao M J, Song Y, Su X B, et al. The key stage and moment of coalbed gas reservoir evolution in the Qinshui basin, China. Chinese Sci Bull, 2005, 50: 110-110

7 Landais P. Assessement of coal potential evolution by experimental simulation of natural coalification. Org Geochem, 1991, 17: 705-710

8 Raymond M, Landais P. Artificial coalification: Comparison of confined pyrolysis and hydrous pyrolysis. Fuel, 1994, 73: 1691-1696

9 Behar F, Vandenbroucke M, Teermann S C, et al. Experimental simulation of gas generation from coals and a marine kerogen. Chem Geol, 1995, 126: 247-260

10 Cramer B. Methane generation from coal during open system pyrolysis investigate by isotope specific, Gaussian distributed reaction kinetics. Org Geochem, 2004, 35: 379-392

11 Duan Y, Wu B X, Zheng C Y, et al. Studies on thermal simulation of the formation and evolution of coalbed gas. Chinese Sci Bull, 2005, 50: $40-44$ 
12 Duan Y, Wu B X, Zheng C Y, et al. Studies on kinetics of hydrocarbon generation from coals in Qinshui basin. Chinese Sci Bull, 2005, 50: 1904-1911

13 Liu Q Y, Liu W H, Dai J X. Characterization of pyrolysates from maceral components of Tarim coals in closed system experiments and implications to natural gas generation. Org Geochem, 2007, 38: 921-934

14 Chen J P, Deng C P, Wang H T, et al. Biomarker and its implication of pyrolysis oils of macerals from Jurassic coal measures, northwest China (in Chinese). Geochimica, 2006, 2: 141-150

15 Behar F, Vandenbroucke M, Teerman S C, et al. Experimental simulation of gas generation from coals and a marine kerogen. Chem Geol, 1995, 126: 247-260

16 Liu Q Y, Liu W H, Qin S F, et al. Geochemical study of thermal simulation on coal and coal with different mediums-Yielding rate of gaseous and organic liquid products and their evolution (in Chinese). Acta Sediment Olog Sin, 2001, 19: 465-468

17 Yao S, Xue C, Hu W, et al. A comparative study of experimental maturation of peat, brown coal and subbituminous coal: Implications for coalification. Int J Coal Geol, 2006, 66: 108-118

18 Rollins M S, Cohen A D, Bailey A M, et al. Organic chemical and petrographic changes induced by early-stage artificial coalification of peats. Org Geochem, 1991, 17: 451-465
19 Kracht O, Gleixner G. Isotope analysis of pyrolysis products from Sphagnum peat and dissolved organic matter from bog water. Org Geochem, 2000, 31: 645-654

20 Stach E, Mackowsky M-Th, Teichmüller M, et al. Stach's Textbook of Coal Petrology. 2nd ed. Berlin: Gebrüder Borntraeger, 1982

21 Stahl J W, Carey B D. Source-rock identification by isotope analyses of natural gases from fields in the Val Verde and Delaware Basins, West Texas. Chem Geol, 1975, 16: 257-267

22 Dai J X, Qi H F. $\delta^{13}$ C- $R_{\mathrm{o}}$ relationship of China's coalbed gas (in Chinese). Chinese Sci Bull, 1989, 34: 690-692

23 Duan Y, Sun T, Liu J F, et al. Thermal simulation experiment and application of staged evolution of coalbed methane carbon isotope (in Chinese). Acta Sediment Sin, 2010, 28: 401-404

24 Sun Z X, Zhang W, Hu B Q, et al. Geothermal field and its relation with coalbed methane distribution of the Qinshui basin. Chinese Sci Bull, 2005, 50: 93

25 Sang S X, Liu H J, Li G Z, et al. Generation and enrichment of coal bed methane I. Gasyield in effective stage and concentration of coal bed methane (in Chinese). Coal Geol Explor, 1997, 25: 14-17

26 Zhao M J, Song Y, Su X B, et al. Key geological time of deciding the geochemical characteristics of coal bed methane (in Chinese). Nat Gas Ind, 2005, 25: 51-54

Open Access This article is distributed under the terms of the Creative Commons Attribution License which permits any use, distribution, and reproduction in any medium, provided the original author(s) and source are credited. 